\title{
Exploring the Gender Gap in Young Adults' Attitudes about Animal Research
}

\section{Linda K. Pifer ${ }^{1}$ \\ CHICAGO ACADEMY OF SCIENCES}

Young adults' attitudes toward the use of animals in scientific research were examined by using data from the Longitudinal Study of American Youth (LSAY). A structural equation model was estimated using LISREL8 to examine the development of these attitudes. Gender was found to have the greatest total effect on opposition to animal research, while feminist attitudes had the second greatest total effect. Feminist attitudes, 10th grade science achievement, adult scientific literacy, general attitudes toward science, partisan affiliation, and a number of early home influences each explained part, but not all of the gender difference in attitudes about scientific research.

One of the most consistent findings in studies of attitudes about animal rights and animal research has been the gender difference. Past studies have found that women are more likely to support the animal rights movement and to oppose animal research than men (Bailey, 1994; Bowd \& Bowd, 1989; Broida, Tingley, Kimball, \& Miele, 1993; Gallup \& Beckstead, 1988; Galvin \& Herzog, 1992; Herzog, Betchart, \& Pittman, 1991; Kellert \& Berry, 1987; Nibert, 1994; Pifer, 1994; Pifer, Shimizu, \& Pifer, 1994; Plous, 1991). The relationship between science attitudes, scientific literacy, and attitudes about animal research may explain, in part, these gender differences. Consistent gender differences have been found in attitudes toward science and technology, with women holding more negative attitudes toward science than men (Fjaestad, 1994; Fox \& Firebaugh, 1992; Kenward, 1989; Trankina, 1993).

The relationship between scientific literacy, attitudes toward science, and attitudes toward animal research has been the subject of frequent discussion. It has been suggested by some that opposition to animal research can be directly linked to the general level of scientific literacy in the United States (Morrison, 1992; "Taking the Offensive," 1990). Others have suggested that opposition to animal research is representative of a broader, anti-instrumental attitude, one that represents disillusionment with science (Nelkin \& Jasper, 1992). 
Jasper and Nelkin (1992) connect the animal rights movement with broader attitudes about science. They suggest that activists from various social movements in the 1980s began to show opposition to science. Such protest movements formed around an anti-instrumental position and an emphasis on moral rather than instrumental values. Younger activists, according to Jasper and Nelkin, are more likely to question accepted scientific practices.

Birke and Michael (1992) found that some scientists explain animal rights activism by the public's anti-science attitudes. Broida, Tingley, Kimball, and Miele (1993) surveyed college students and found that faith in science was the best predictor of attitudes about animal research.

In addition to general attitudes about science, scientific knowledge and scientific literacy have also been associated with attitudes about animal research (Birke \& Michael, 1992; Morrison, 1992; "Taking the Offensive," 1990). Pifer, Shimizu, and Pifer (1994) found an inconsistent relationship between a knowledge of scientific concepts and opposition to animal research across 14 nations. Pifer (1994) found the relationship between adolescents' science achievement scores and their opposition or support of animal research varied based on gender.

Younger adults have been found to be more likely to support animal rights than are older adults (Bailey, 1994; Nibert, 1994). This article uses data from the Longitudinal Study of American Youth to examine the precursors of young adults' attitudes about animal research. In particular, the relationship between gender, scientific literacy, attitudes toward science, and attitudes toward animal research will be examined.

\section{Method}

\section{Data Source}

This article presents a secondary analysis of data obtained from the Longitudinal Study of American Youth (LSAY) ${ }^{2}$ (Miller et al., 1992). During the seven years between 1987 and 1994 the LSAY collected a wide array of data from two cohorts of individuals, each composed of approximately 3,000 youth. The study focused on the development of attitudes and competence in science, mathematics, and citizenship.

The LSAY consisted of a probability sample of 52 middle schools and 51 high schools throughout the nation. The LSAY used a two-stage stratified probability sampling scheme. The United States was first stratified into four geographic areas (northeast, north central, south, and west). Then, each of the geographic areas was 
stratified by level of urban development (urban, suburban, and nonmetropolitan), for a total of 12 strata. Stage I consisted of the selection of schools to participate in the study, while Stage II involved the selection of students within the schools.

As the LSAY sample is not a simple random sample, students did not have equal probabilities of being included in the study. Weight variables were constructed for each year of the study. These weight variables must be used in all analyses in order to obtain correct estimates of national distributions. All analyses in the current study were weighted by the appropriate weight variable.

The focus of this article is on cohort one of the LSAY. Cohort one youth were in the 10th grade in the Fall of 1987 when the study began. In year seven of the LSAY, 2,037 members of cohort one (72 percent of the original cohort) participated in the study: 1,850 completed a telephone interview, 149 completed a long-form mailed questionnaire, and another 38 individuals completed a short-form questionnaire. The two mailed questionnaires did not include all of the items used in the present study, therefore only those individuals who completed the telephone interview in year seven of the LSAY, a total sample size of 1,850 individuals, were included in this analysis.

\section{Analysis Methods}

Many factors that are believed to contribute to attitudes about animal research are highly correlated. The interrelated nature of these factors makes it appropriate to examine the development of these attitudes within a multivariate context. A multivariate analysis allows one to determine the relative influence of each of several factors in explaining attitudes about animal research. To estimate the relative impact of each of several possible explanatory variables on young adults' attitudes about animal research, a structural equation model was constructed and estimated with the LISREL8 program (Joreskog \& Sorbom, 1993). In order to treat the ordinal variables included in the study properly, the raw data were produced as a matrix of polychoric, polyserial correlations, which was read into LISREL8 (see Appendix). Before turning to the results of this model, it is useful to turn first to a description of the explanatory variables used in the model and then to the measurement of the outcome variable.

\section{The Explanatory Variables}

In the model developed for this analysis, each individual's gender, the highest level of education attained by either of the individual's parents, and rural residence 
during adolescence were taken as temporally and logically prior to their attitudes about animal research. The relationship between gender and attitudes about animal research has been well documented. Mixed results have been found for rural residence and attitudes about animals (Kellert, 1988; Sieber, 1986). Previous analyses of LSAY data have found parent education to be strongly and positively related to a variety of outcome factors including science achievement, mathematics achievement, educational expectations, career choice, and interest in public policy issues (Miller \& Brown, 1992; Miller \& Green, 1994).

One task of a structural equation analysis is to identify the intervening variables that account for, or explain, the bivariate correlations between background variables such as gender, parent education, and place of residence, and outcome measures such as attitudes toward animal research. Two blocks of explanatory, or intervening, variables were introduced into the model between the background variables and attitudes about animal research. The first group of intervening variables represents attitudes and influences that occurred during high school, and the second represents experiences and general attitudes during young adulthood.

Four high school influences were included in the first block of intervening variables: home science resources, parent science "push," early feminist attitudes, and 10th grade science achievement. The home science resources index (HSCRE1) is a count of the number of science resources the student reported having in their home in grade ten. The six resources included in the index are a computer, an atlas or globe, a pocket calculator, more than 50 books, a microscope, and a telescope. The home science resources index has a reliability of .69 (Cronbach's alpha). Previous analyses of LSAY data have found early home influences to have a strong, positive relationship with educational expectations, career choice, science and mathematics achievement, and persistence in science and mathematics courses (Miller \& Brown, 1992; Miller \& Green, 1994; Reynolds \& Walberg, 1991; Reynolds, 1991).

Parent science push in grade ten (PSCPH1) is an index ranging from zero to three and is composed of the following items from the "my parents" series of questions: (1) have always encouraged me to work hard on science; (2) expect me to do well in science; and (3) think science is important. Parent science push has a reliability of .73 (Cronbach's alpha).

Broida, Tingley, Kimball, and Miele (1993) found that masculine personality types were less likely to oppose animal research than were feminine types. Similarly, Herzog, Betchart, and Pittman (1991) found that both gender and feminine sex role orientation explain a portion of attitudes regarding animals. Pifer 
(1994) found that adolescent girls who opposed animal research had higher scores on an index of feminist attitudes than did girls who supported animal research. During high school, the LSAY respondents were asked to indicate whether they strongly agreed, agreed, disagreed, or strongly disagreed with a series of statements. The following items were included in the index of feminist attitudes used in this analysis (FEMINIST):

- In a good marriage, a man's career and a woman's career are of equal importance.

- It is usually better for everyone involved if the man is the achiever outside the home and the woman takes care of the family.

- It is more important for a woman to help her husband's career than to have one of her own.

- In a family with preschool children, the husband should work full-time and the wife should work no more than half-time.

- If a woman earns more money than her husband, the marriage is likely to be headed for trouble.

Each fall while they were in middle school and high school LSAY youths were given a science test. These tests were constructed from National Assessment of Educational Progress (NAEP) items. 10th grade science achievement (ASCILSAY) was inserted in the model as an early measure of science knowledge.

Four measures of young adult influences and attitudes were included in the second block of intervening variables: scientific literacy, attitudes toward organized science, partisan identification, and educational status. The measure of scientific literacy used in this analysis (SSCILIT7) was created based on Miller's conceptualization of scientific literacy. Miller (1992) defined a scientifically literate individual as one who has: (1) a basic vocabulary of scientific and technical terms and concepts; (2) an understanding of the process or methods of science for testing our models of reality; and (3) an understanding of the impact of science and technology on society. The Attitude Toward Organized Science Scale (SATOSS7) combines the following four items into a summary measure of an individual's general attitude toward organized science:

- Agreement that "science and technology are making our lives healthier, easier and more comfortable."

- Agreement that "the benefits of science are greater than any harmful effects." 
- Disagreement that "science makes our way of life change too fast."

- Disagreement that "we depend too much on science and not enough on faith." The scale has been collected in the National Science Foundation's Science and Engineering Indicators studies since 1983 (Miller, 1992).

Previous studies have found liberalism to be associated with opposition to animal research (Broida, Tingley, Kimball, \& Miele 1993). The LSAY interviews did not include questions about political ideology, but did include questions about partisan identification (SPARTY7). For purposes of this analysis respondents were coded as " 1 " if they identified themselves as being a Republican, and " 0 " for Independent and Democrat.

Bailey (1994) found that animal rights supporters tended to have lower levels of education than did animal rights opponents. Kellert and Berry (1987) found higher levels of education were associated with protectionist sentiments toward animals. The measure used here (EDSTAT7) is a combination of each respondent's current level of education, as well as their plans for future education. The combined measure has the following four levels: (1) high school or less; (2) some college or intends to complete some college; (3) currently enrolled in college and intends to obtain a baccalaureate; and (4) currently enrolled in college and intends to obtain a graduate degree.

\section{Measurement of Opposition to Animal Research}

The 1994 LSAY interviews included a series of questions designed to measure the young adults' attitudes about various scientific and technological topics. Embedded within this battery of items were the following three questions regarding the use of animals in scientific research:

- Scientists should be allowed to do research that causes pain and injury to animals like dogs and chimpanzees if it produces new information about human health problems. Do you strongly agree, agree, disagree, or strongly disagree?

- Continued research with animals will be necessary if we are to ever conquer diseases such as cancer, heart disease, and AIDS. Do you strongly agree, agree, disagree, or strongly disagree?

- Most of the scientific research done with animals is unnecessary and cruel. Do you strongly agree, agree, disagree, or strongly disagree? 
Table 1. Opposition to the Use of Animals in Scientific Research by Selected Factors'

Percent Opposed to Animal Research

\section{Factor \\ Total \\ Gender}

Male

Female

Scientific Literacy

Not literate

Literate

Attitude Toward Organized Science

0 (Anti-science)

1

2

3

4 (Pro-science)

Partisan Identification

Democrat

Independent

Republican

Pro-Feminist Attitude

Low

Medium

High

$\begin{array}{rrrr}\text { A } & \text { B } & \text { C } & \text { N } \\ 61 \% & 32 \% & 55 \% & 1850\end{array}$

$\begin{array}{llll}48 & 24 & 46 & 866\end{array}$

$\begin{array}{llll}73 & 41 & 63 & 957\end{array}$

$\begin{array}{llll}62 & 34 & 58 & 1622\end{array}$

$\begin{array}{llll}51 & 16 & 31 & 186\end{array}$

$\begin{array}{llll}82 & 60 & 91 & 44\end{array}$

$\begin{array}{llll}66 & 43 & 76 & 201\end{array}$

$\begin{array}{llll}65 & 33 & 66 & 357\end{array}$

$\begin{array}{llll}60 & 30 & 53 & 514\end{array}$

$\begin{array}{llll}58 & 29 & 44 & 691\end{array}$

$\begin{array}{llll}67 & 30 & 61 & 473\end{array}$

$\begin{array}{llll}65 & 37 & 60 & 733\end{array}$

$\begin{array}{llll}53 & 29 & 45 & 601\end{array}$

$\begin{array}{llll}50 & 24 & 46 & 370\end{array}$

$\begin{array}{llll}60 & 31 & 53 & 629\end{array}$

$\begin{array}{llll}70 & 40 & 63 & 445\end{array}$

Note:

$A=$ "Scientists should be allowed to do research that causes pain and injury to animals like dogs and chimpanzees if it produces new information about human health problems." ( Disagree)

$B=$ "Continued research with animals will be necessary if we are to ever conquer diseases such as cancer, heart disease, and AIDS." (Disagree)

$\mathrm{C}=$ "Most of the scientific research done with animals is unnecessary and cruel." (Agree)

'All differences in this table are significant at the .01 level as measured by $\chi^{2}$. 
The first question has been included in a series of surveys conducted in the United States and funded by the National Science Foundation since 1988. This same question has been replicated in surveys conducted in Canada, Japan, and the European Community (Pifer, Shimizu, \& Pifer, 1994). The latter two questions are taken from the Animal Attitude Scale (Herzog, Betchart, \& Pittman; 1991). Significant differences were found in opposition to animal research on the basis of gender, scientific literacy, general attitudes toward science, partisan identification, and feminist attitudes for each of the three questions (see Table 1).

An analysis of the scalar characteristics of the three items indicated that they formed an acceptable scale. Exploratory factor analysis produced factor loadings all greater than .67 , while the reliability (Cronbach's alpha) was .78. An index of opposition to animal research was created by giving respondents one point for opposing animal research in each of the three items. The index ranges from zero to three, and has a mean of 1.46 and a standard deviation of 1.16 (see Table 2).

Consistent with previous research, young women were more likely to oppose animal research (1.74) than were men (1.16). Individuals with positive general attitudes toward science were less likely to oppose animal research than were those with negative attitudes toward science. Scientifically literate individuals were also less likely to oppose animal research (.96) than were those who were not scientifically literate (1.52). Republicans were less likely to oppose animal research (1.26) than either Democrats (1.55) or Independents (1.57). Finally, individuals who had high scores on the feminist index were more likely to oppose animal research than were those with low scores (see Table 2).

\section{Results}

The construction and testing of a structural equation model provide for estimates of the relative size of the explained, residual, and total effects of each independent variable in the model on the outcome variable. Looking first at the relative size of the total effects of each independent variable, it can be seen that gender had the greatest total effects on opposition to animal research of .43 (see Table 3). Feminist attitudes had the second greatest total effects of .23. The two measures of scientific knowledge-science achievement in grade twelve, and scientific literacy as an adult - had nearly identical total effects of -.21 and -.20 . The negative sign of these effects indicates that individuals with higher levels of science knowledge were less likely to oppose animal research. General attitudes toward organized science had similar effects of -.16. All of the other factors included in the model, with the exception of 
Table 2. Opposition to the Use of Animals in Scientific Research by Selected Factors

\begin{tabular}{|c|c|c|c|c|}
\hline Factor & Mean & SD & $\mathbf{N}$ & Analysis of Variance \\
\hline Total & 1.46 & 1.16 & 1850 & \\
\hline Gender & & & & $F=119.39, d f=1, p<.01$ \\
\hline Male & 1.16 & 1.12 & 880 & \\
\hline Female & 1.74 & 1.13 & 971 & \\
\hline Scientific Literacy & & & & $F=40.54, d f=1, p<.01$ \\
\hline Not literate & 1.52 & 1.15 & 1660 & \\
\hline Literate & .96 & 1.06 & 190 & \\
\hline \multicolumn{4}{|c|}{ Attitude Toward Organized Science } & $F=14.06, d t=4, p<.01$ \\
\hline 0 (Anti-science) & 2.00 & 1.15 & 124 & \\
\hline 1 & 1.82 & 1.07 & 370 & \\
\hline 2 & 1.62 & 1.10 & 667 & \\
\hline 3 & 1.40 & 1.17 & 504 & \\
\hline 4 (Pro-science) & 1.28 & 1.17 & 185 & \\
\hline Partisan Identification & & & & $F=14.42, d f=2, p<.01$ \\
\hline Democrat & 1.55 & 1.07 & 485 & \\
\hline Independent & 1.57 & 1.17 & 758 & \\
\hline Republican & 1.26 & 1.19 & 608 & \\
\hline Pro-Feminist Attitude & & & & $F=22.11, d f=2, p<.01$ \\
\hline Low & 1.19 & 1.13 & 377 & \\
\hline Medium & 1.41 & 1.14 & 637 & \\
\hline High & 1.71 & 1.15 & 451 & \\
\hline
\end{tabular}

Note: The index of opposition to animal research was created by giving respondents one point for opposing animal research in each of the three items. The index ranges from zero to three, with a score of three representing opposition to animal research and zero representing support of animal research.

rural residence, had lesser, but significant, effects on opposition to animal research. The model had a good fit with a Root Mean Square Error of Approximation of .024, with a confidence interval between .014 and .034 , and an Adjusted $\chi^{2}$ of $2.06\left(\chi^{2}\right.$ of 45.32 divided by 22 degrees of freedom). 
Table 3. Estimates of the Direct, Indirect, and Total Effects of Selected Factors on Young Adults' Opposition to the Use of Animals in Scientific Research

Variable

Direct Effects Indirect Effects Total Effects

Background Influences

Female

Parent Education

Rural

High School Influences

Home Science Resources

Parent Science Push

Feminist Attitudes

Science Achievement Grade 10

Young Adult Influences

Scientific Literacy

Attitude Toward Organized Science

Republican

Educational Status-1994

.23

.00

.00

.00

.00

.22

.00

$-.20$

$-.16$

$-.06$

$-.10$
.43

. .13

$\begin{array}{rr}.00 & .13\end{array}$

.20

$-.07$

$-.01$

.23

$-.21$

$-.20$

$-.16$

$-.06$

$-.10$

The effects of gender on opposition to animal research provide a useful illustration of the separation of effects into explained (or indirect) and residual (or direct) effects. Looking at the path diagram (Figure 1) it can be seen that being female is positively associated with feminist attitudes (.53), which in turn are positively associated with opposition to animal research (.22). This relationship indicates that a part of the bivariate relationship between gender and opposition to animal research is explained by the propensity of adolescent females to hold more pro-feminist attitudes than adolescent males.

Women were slightly less likely than men to identify themselves as Republican (-.13). Republicans, in turn, were slightly less likely (-.06) to oppose animal research. Women were also slightly less likely than men (-.11) to be scientifically literate as young adults, and the scientifically literate were less likely $(-.20)$ to oppose animal research. Young women tended to score lower on their 10th grade science achievement test (-.23) than young men. Early science achievement has a positive relationship with the young adults' general attitudes toward organized science (.39), which in turn is negatively associated with opposition to animal research (-.16). Young women had slightly higher levels of education than young 


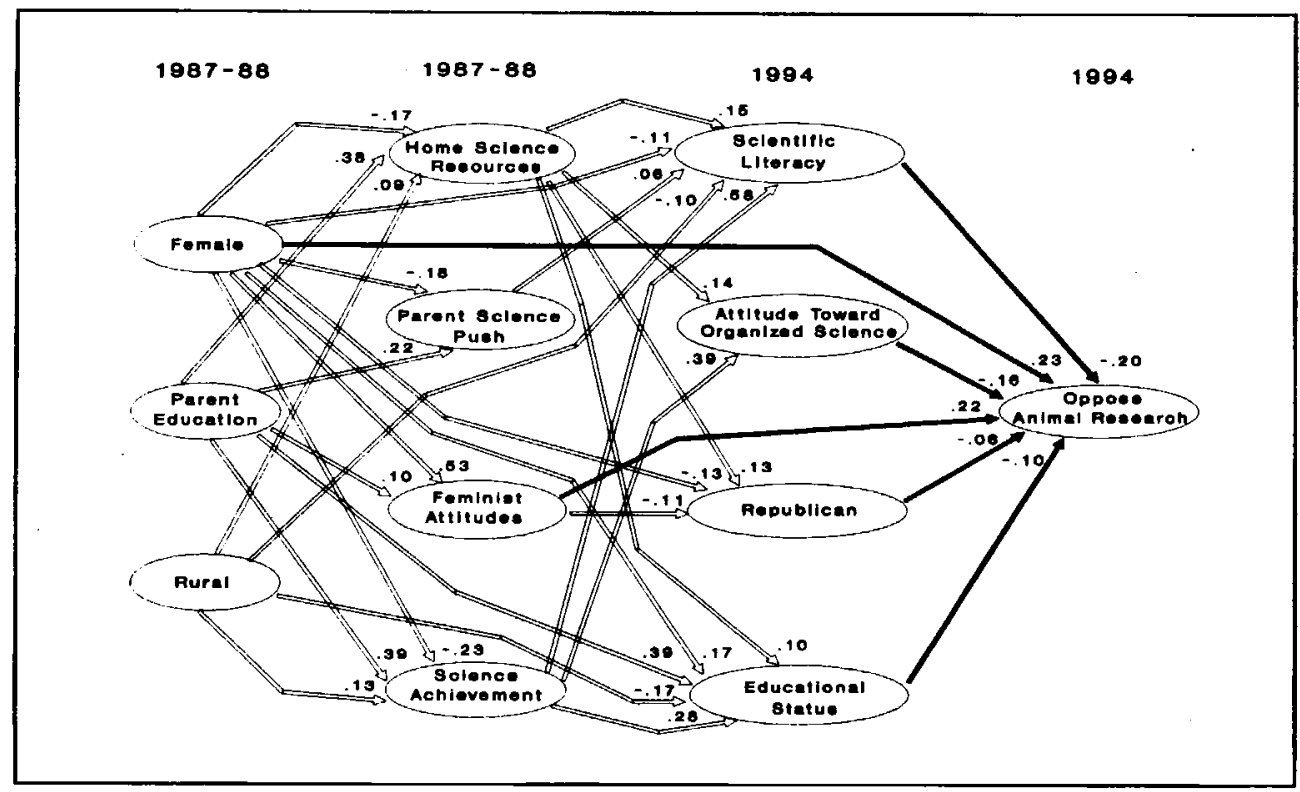

Figure 1. The effects of selected factors on opposition to animal research

men (.17), which was negatively related to opposition to animal research $(-.10)$.

Early parental influences also play a role in explaining gender differences in attitudes toward animal research. Parents were less likely to encourage their daughters in science (-.18) and to provide home science resources for them (-.17). Both of these factors are positively associated with scientific literacy. Additionally, home science resources is positively associated with general attitudes toward science (.14), educational status (.10), and Republican affiliation (.13), each of which has a negative relationship with opposition to animal research.

Even when all other independent variables are held constant, there remains a strong, positive relationship between being female and opposition to animal research (.23). This residual effect means that, even taking into account all factors included in the model, a young woman is more likely to oppose animal research than a young man. A strong, residual path from any basic background variable to an outcome variable indicates that other intervening variables need to be examined to help explain the effects on the outcome variable. 


\section{Discussion and Conclusions}

Studies of attitudes toward animal research have consistently shown that women are more likely to oppose animal research than men. This study examined several possible explanations for these gender differences. Early parental influences, early feminist attitudes, scientific literacy, and general attitudes toward science were offered as possible intervening variables to explain the relationship between gender and attitudes about animal research.

A portion of the gender difference in attitudes about animal research can be explained by early parental influences. Adolescent girls reported receiving lower levels of encouragement in science than did boys. Additionally, girls reported that their parents provided them with fewer home science resources than did boys. Each of these factors had a small, but significant, effect on opposition to animal research. Individuals who received parental encouragement in science while in high school were less likely to oppose animal research as young adults.

As would be expected, adolescent females were much more likely than adolescent males to express feminist attitudes while in high school. These early feminist attitudes were found to have an enduring effect on young adults' attitudes about animal research.

General attitudes toward science were also found to have a significant effect on attitudes about animal research. Young adults were less likely to oppose animal research who agreed that science and technology are making our lives healthier, easier and more comfortable, and that the benefits of science are greater than any harmful effects. At the same time, they disagreed that science makes our way of life change too fast, and that we depend too much on science and not enough on faith.

Finally, a relationship was found between scientific literacy and attitudes about animal research. Adolescents who performed at higher levels on high school science achievement tests were more likely to be scientifically literate as young adults. Scientifically literate young adults were less likely to oppose animal research than were those who were not scientifically literate.

It is clear from this analysis that there is a substantial relationship between early socialization to success in science, scientific attitudes, scientific literacy, and attitudes about animal research. However, these factors do not completely explain the propensity for young women to oppose animal research more frequently than young men. Young women do not oppose animal research simply because they know less about science than young men. Feminist attitudes and partisan affiliation also explain a portion of the gender difference in attitudes about animal research. This study found a strong relationship between pro-feminist attitudes and opposi- 
tion to animal research. It also found a weak relationship between Republican partisan identification and support for animal research. Both of these findings suggest further exploration is needed of the relationship between policy dispositions regarding social issues and attitudes toward animal research.

Finally, a substantial residual relationship was found between gender and attitudes about animal research. Even taking into account gender differences in feminist attitudes, attitudes about science, scientific literacy, and early encouragement in science, women were still more likely than men to oppose animal research. This finding suggests the need to examine other possible explanations for the gender difference in attitudes about animal research. Two possible areas for further exploration are: other measures of feminist attitudes and a private (or nurturance) emphasis as opposed to a public emphasis.

The measure of feminist attitudes used in this study focuses on gender equality, primarily as it relates to careers. Previous studies have found that support for feminism as a political ideology helps explain gender differences in attitudes about a variety of political issues (Conover, 1988; Sears \& Huddy, 1988). Conover notes that women who identify themselves as feminists are more likely to be sympathetic to the disadvantaged. Such a concern for the disadvantaged could be easily extended to concern for animal rights, and may help explain some of the gender difference in attitudes about animal research.

Other researchers have suggested that gender differences in political attitudes and interests can be explained by the differential emphasis of men and women on the private or public sphere (Sapiro, 1981; Burns \& Schumaker, 1987). According to this approach, men tend to be concerned with the public sphere, and such issues as business, competition, and power. In contrast, women tend to focus on the private sphere, and such issues as social welfare and nurturance. Deitch (1988) suggests that feminists have attempted to extend women's values of nurturance and compassion to the political arena. The gender difference in attitudes about animal research may be partially explained by the differential emphasis of women on nurturance or compassion.

\section{Notes}

1. Address all correspondence to the author at International Center for the Advancement of Scientific Literacy, Chicago Academy of Sciences, 2001 North Clark Street, Chicago, IL 60614, email: 1kpifer@mcs.com.

2. The LSAY was funded by the National Science Foundation (grant MDR-8550085). The analysis and conclusions presented in this paper are those of the author and do not necessarily reflect the views of the National Science Foundation or its staff. 
3. The actual variable names, as they appear in the LSAY data set, are provided in parentheses. A more complete description of these variables is available in Miller et al.

\section{References}

Bailey, M. (1994, April). Women and support for the animal rights movement, 1948-1985. Paper presented at the meeting of the Midwest Political Science Association, Chicago, IL.

Birke, L., \& Michael, M. (1992, April 4). Views from behind the barricade. New Scientist, 29-32.

Bowd, A. D., \& Bowd, A. C. (1989). Attitudes toward the treatment of animals: A study of Christian groups in Australia. Anthrozoös, 3, 20-24.

Broida, J., Tingley, L., Kimball, R., \& Miele, J. (1993). Personality differences between pro- and anti-vivisectionists. Society and Animals, 1, 129-144.

Burns, N. E., \& Schumaker, P. (1987). Gender differences in attitudes about the role of local government. Social Science Quarterly, 68, 138-147.

Conover, P. J. (1988). Feminists and the gender gap. Journal of Politics, 50, 985-1010.

Deitch, C. (1988). Sex differences in support for government spending. In C. M. Mueller (Ed.), The politics of the gender gap: The social construction of political influence (pp. 192-216). Newbury Park: Sage Publications.

Fjaestad, B. (1994, November). The 1994 Swedish survey on public understanding of science. Paper presented at the International Conference on the Public Understanding of Science and Technology, London.

Fox, M. F., \& Firebaugh, G. (1992). Confidence in science: The gender gap. Social Science Quarterly, 73, 101-113.

Gallup, G. G., Jr., \& Beckstead, J. W. (1988). Attitudes toward animal research. American Psychologist, 43, 474-476.

Galvin, S. L., \& Herzog, H. A., Jr. (1992). Ethical ideology, animal rights activism, and attitudes toward the treatment of animals. Ethics and Behavior, 2, 141-149.

Herzog, H. A., Jr., Betchart, N. S., \& Pittman, R. B. (1991). Gender, sex role orientation, and attitudes toward animals. Anthrozoös, 4, 184-191.

Jasper, J. M., \& Nelkin, D. (1992). The animal rights crusade: The growth of a moral protest. New York: The Free Press.

Joreskog, K., \& Sorbom, D. (1993). LISREL8: Structural Equation Modeling with the SIMPLIS Command Language. Hillsdale, NJ: Lawrence Erlbaum Associates.

Kellert, S. R. (1988). Human-animal interactions: A review of American attitudes to wild and domestic animals in the twentieth century. In A. N. Rowan (Ed.), Animals and people sharing the world (pp. 137-175). Hanover, NH: University Press of New England.

Kellert, S. R., \& Berry, J. K. (1987). Attitudes, knowledge, and behaviors toward wildlife as affected by gender. Wildlife Society Bulletin, 15, 363-371. 
Kenward, M. (1989). Science stays up the poll. New Scientist, 16, 57-61.

Miller, J. D. (1992). The public understanding of science and technology in the United States, 1990. Report to the National Science Foundation. Washington, DC: Division of Science Resources Studies, NSF.

Miller, J. D., \& Brown, K. G. (1992). The development of career expectations by American youth. In W. Meeus, M. de Godede, W. Kox, \& K. Hurrelmann (Eds.). Adolescence, careers, and cultures (pp. 217-241). Berlin: Walter de Gruyter.

Miller, J. D., \& Green, H. (1994, April). The influence of family and home on student persistence and achievement in science and mathematics. Paper presented at the 1994 Conference of the American Educational Research Association, New Orleans, LA.

Miller, J. D., Hoffer, T., Suchner, R. W., Brown, K. G., \& Nelson, C. (1992). LSAY codebook: Student, parent, and teacher data for cohort one for longitudinal years one through four (1987-1991). DeKalb, IL: Northem Illinois University.

Morrison, A. R. (1992). What's wrong with “animal rights”. Education Digest, 57, 57-60.

Nelkin, D., \& Jasper, J. M. (1992). The animal rights controversy. In D. Nelkin (Ed.). Controversy: Politics of technical decisions (pp. 26-44). Newbury Park: Sage Publications.

Nibert, D. A. (1994). Animal rights and human social issues. Society and Animals, 2, $115-$ 124.

Pifer, L. (1994). Adolescents and animal rights: Stable attitudes or ephemeral opinions. Public Understanding of Science, 3, 291-307.

Pifer, L., Shimizu, K., \& Pifer, R. (1994). Public attitudes toward animal research: Some international comparisons. Society \& Animals, 2, 95-113.

Plous, S. (1991). An attitude survey of animal rights activists. Psychological Science, 2, 194-196.

Reynolds, A. J. (1991). The middle schooling process: Influences on science and mathematics achievement from the Longitudinal Study of American Youth. Adolescence, 26, 133-158.

Reynolds, A. J., \& Walberg, H. J. (1991). A structural model of science achievement. Journal of Educational Psychology, 83, 97-107.

Sapiro, V. (1981). When are interests interesting? The problem of political representation of women. The American Political Science Review, 75, 701-716.

Sears, D. O., \& Huddy, L. (1988, April). On the origins of the political disunity of women. Paper presented at the meeting of the Midwest Political Science Association, Chicago, IL.

Sieber, J. E. (1986). Students' and scientists' attitudes on animal research. The American Biology Teacher, 48, 85-91.

Taking the offensive for animal research. (1990). BioScience, 40, 43.

Trankina, M. (1993). Gender differences in attitudes toward science. Psychological Reports, 73, 123-130. 


\section{Appendix}

Matrix of Polychoric, Polyserial Correlations Used in LISREL8

\begin{tabular}{|c|c|c|c|c|c|c|c|c|c|c|c|c|}
\hline & 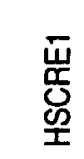 & 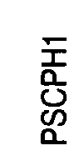 & 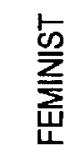 & 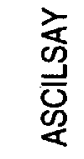 & $\underset{\text { 导 }}{\stackrel{\Xi}{\bar{D}}}$ & 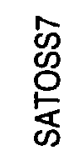 & $\frac{\sum}{\frac{\mathbf{c}}{\alpha}}$ & 桌 & $\begin{array}{l}\text { 岁 } \\
\text { 욤 } \\
\text { 잉 }\end{array}$ & 崖 & $\begin{array}{l}\text { 号 } \\
\text { 㟒 }\end{array}$ & $\begin{array}{l}\underset{\mathbb{x}}{\mathbb{x}} \\
\underset{\underline{\underline{x}}}{\not{x}}\end{array}$ \\
\hline HSCRE1 & 1.00 & & & & & & & & & & & \\
\hline PSCPH 1 & .25 & 1.00 & & & & & & & & & & \\
\hline FEMINIST & .01 & .04 & 1.00 & & & & & & & & & \\
\hline ASCILSAY & .39 & .22 & .09 & 1.00 & & & & & & & & \\
\hline SSCILIT7 & .36 & .24 & .03 & .59 & 1.00 & & & & & & & \\
\hline SATOSS7 & .21 & .13 & .03 & .34 & .30 & 1.00 & & & & & & \\
\hline SPARTY7 & .11 & .00 & -13 & .09 & .02 & .07 & 1.00 & & & & & \\
\hline EDSTAT7 & .25 & .16 & .11 & .36 & .40 & .29 & .05 & 1.00 & & & & \\
\hline OPPOSE & -.11 & -.12 & .21 & -.17 & -.27 & -.20 & -.12 & -.16 & 1.00 & & & \\
\hline FEMALE & -.15 & -.16 & .43 & -.22 & .25 & -.09 & -.18 & .05 & .33 & 1.00 & & \\
\hline PEDUC3 & .28 & .19 & .05 & .32 & .23 & .18 & .06 & .47 & -.08 & -.05 & 1.00 & \\
\hline RURAL & -.03 & -.08 & -.03 & .00 & -.11 & -.04 & -.01 & -.26 & .04 & .04 & -.30 & 1.00 \\
\hline
\end{tabular}

